\title{
Physicochemical properties and immunomodulatory effects of polysaccharides isolated from Styela plicata
}

\author{
Dae-Hoon Lee, Joo-Heon Hong * \\ Department of Food Science and Technology, Daegu Catholic University, Gyeongsan 38430, Korea
}

\begin{abstract}
The physicochemical properties and immunomodulatory effects of polysaccharides isolated from the sea squirt Styela plicata were investigated. The crude polysaccharide (SP) was further fractionated into an unabsorbed fraction (SF-1) and absorbed fractions (SF-2 and SF3) to isolate polysaccharides with different molecular weights. The major constituents in the crude and fractionated polysaccharides were total carbohydrate (28.03-42.65\%), uronic acid $(9.88-23.76 \%)$, sulfate $(18.03-29.25 \%)$, and protein $(1.48-26.47 \%)$. The average molecular weights of the fractionated polysaccharides ranged from 28 to $1,187 \mathrm{kDa}$. The significant monosaccharide components of the polysaccharides were galactose (27.91-62.21\%), glucose (14.79-37.63\%), and glucosamine (10.74-28.31\%). FT-IR analysis indicates that SP, SF-1, SF-2, and SF-3 were sulfated polysaccharides. SF-1 increased the production of nitric oxide and cytokines, such as tumor necrosis factor alpha and interleukin 6, in a dose-dependent manner in RAW 264.7 cells. Further, polymerase chain reaction analysis revealed that the mRNA expression of inducible NO synthase (iNOS) and cyclooxygenase-2 (COX-2) was markedly increased. These results indicate that SF-1 can enhance the activation of macrophages and that increasing the molecular weight and the uronic acid and sulfate content of fractionated polysaccharides can enhance their immunomodulatory function.
\end{abstract}

Key words : Styela plicata, polysaccharides, nitric oxide, cytokines, immunomodulatory effect

\section{Introduction}

The immune system is essential for health and is a complex system of tissues, cells, and molecules that mediate resistance to infections (1). Immunostimulation is regarded as a potential strategy to enhance the body's defense mechanism, especially in elderly people and cancer patients. Therefore, the search for biomaterials that can activate and increase immune function has increased in the immunopharmacological and therapeutic research communities. In particular, the role of activated macrophages in defense against tumor cells has been investigated extensively. Activated macrophages has been shown to recognize and lyse tumor cells, including those that are resistant to chemotherapeutic drugs (2). Moreover, macrophages play an important role in regulating the innate

*Corresponding author. E-mail : jhhong@cu.ac.kr

Phone : 82-53-850-3218, Fax : 82-53-850-3218

Received 05 March 2019; Revised 26 March 2019; Accepted 27 March 2019.

Copyright (c) The Korean Society of Food Preservation. All rights reserved. and adaptive immune responses via the production of cytokines, such as interleukin-1 $\beta$ (IL-1 $\beta$ ), interleukin-6 (IL-6), tumor necrosis factor- $\alpha$ (TNF- $\alpha$ ), and interferon- $\gamma$ $($ IFN- 8$)(3,4)$

Polysaccharides are macromolecules produced by most living organisms, including plants, animals, marine algae, mushrooms, microorganisms; therefore, they are also known as biomacromolecules and are widely distributed in nature (5). These polysaccharides are composed of monosaccharides linked together through glycosidic bonds. As well as serving as energy reserve and structural components, polysaccharides participate in signal recognition and cell-cell communication (6). In addition, polysaccharides have been shown to possess immunomodulatory activity through their ability to modulate macrophage function (7). As a result, polysaccharides can influence specific, non-specific, humoral, and cellular immunities (8). The fact that polysaccharides can profoundly affect the immune system, makes them immunomodulators with potentially broad clinical applications (9). Recently, because of relatively limited resources, many researchers have focused on searching for novel compounds with biological 
activity amongst the natural marine resources. Ascidians (commonly known as sea squirts) are known to contain many bioactive compounds with significant pharmaceutical and biomedical potential (10). Previous studies have revealed the abundance of bioactive substances present in ascidians, as well as their antioxidant, anticancer, and immunomodulatory activities (11-13). Styela plicata is a solitary, hermaphroditic ascidian species that is commonly found in ports, harbors and marina, usually in high density. $S$. plicata is considered an introduced species in many regions of the world $(14,15)$. $S$. plicata extract has antigenotoxic and anticarcinogenic effects, minimizing colon carcinogenesis (16). Further, compounds isolated from $S$. plicata can activate phagocytosis and increase IL-2 secretion by mammalian peripheral blood mononuclear cells (17).

In the present study, we extracted polysaccharides from $S$. plicata and isolated three fractions (designated SF-1, SF-2, and SF-3). The analysis of the immunomodulatory effects on murine-derived macrophages demonstrated that the polysaccharides of $S$. plicata activate the production of nitric oxide and cytokines.

\section{Materials and methods}

\section{Materials}

$S$. plicata was purchased from a local supermarket (Daegu, Korea). The $S$. plicata was thoroughly washed with water and dried in hot air $\left(50^{\circ} \mathrm{C}\right)$. The dried samples were milled using a Wiley-type cutting mill (J-NCM; Jisico Co., Seoul, South Korea), sieved $(<0.5 \mathrm{~mm})$, and stored at $-20^{\circ} \mathrm{C}$ before the extraction of the polysaccharides. The enzyme neutrase (0.8 AU/g) was donated by Novo Co. (Novozyme Nordisk, Bagsvaerd, Denmark). Dextran, pullulans, glucose, Dglucuronic acid, potassium sulfate, and bovine serum albumin (BSA) were purchased from Sigma-Aldrich Co. (St. Louis, MO, USA). All other chemicals were of the highest grade available commercially.

\section{Crude polysaccharide extraction}

The $S$. plicata powder $(100 \mathrm{~g})$ was suspended in $2 \mathrm{~L}$ of distilled water. Then, $2 \%$ of neutrase (enzyme to substrate ratio) was added. The hydrolytic reaction was performed for $15 \mathrm{~h}$ at $60^{\circ} \mathrm{C}$. After centrifugation at 3,000 rpm for $30 \mathrm{~min}$ (Supra 30K; Hanil Science Industrial Co., Seoul, South Korea) to remove debris, the filtrate was concentrated in a rotary evaporator, and then precipitated with five volumes of $95 \%$ ethanol for $24 \mathrm{~h}$ at $4^{\circ} \mathrm{C}$. The precipitate was acquired after centrifugation and dissolved in distilled water.

\section{Fractionation of crude polysaccharide}

The crude polysaccharide (200 mg), denoted SP, was dissolved in distilled water $(10 \mathrm{~mL})$, and the solution was injected into a DEAE-Sepharose CL-6B column (GE Healthcare Bio-Science AB, Uppsala, Sweden). The polysaccharide was eluted with distilled water to obtain a non-adsorbed fraction and subsequently developed by stepwise $\mathrm{NaCl}$ gradient $(0-1.0 \mathrm{M})$ to elute the polyanionic polysaccharides. The three fractions obtained by the chromatographic separation, denoted SF-1, SF-2, and SF-3, were dialyzed (molecular weight cut-off (MWCO) 14,000) against distilled water and lyophilized.

\section{Chemical analysis}

The total carbohydrate content of the polysaccharides was determined by the phenol-sulfuric acid method (18) using glucose as a standard. The uronic acid content was determined by the carbazole reaction (19) using D-glucuronic acid as a standard. The sulfate content was determined by the $\mathrm{BaCl}_{2}$-gelatinmethod (20) using potassium sulfate as a standard. Protein was determined by Lowry method (21) using BSA as a standard.

\section{Determination of molecular weight}

The average relative molecular mass of fractionated polysaccharides was estimated by size-exclusion high-performance liquid chromatography (HPLC, Dionex, Sunnyvale, CA, USA) using a Shodex OHpak column (SB-806HQ, 8.0×300 mm, Showa Denko Co., Tokyo, Japan). In this process, $10 \mu \mathrm{L}$ of each sample $(1 \%$, w/v, in water) was injected, eluted with water at a flow rate of $0.8 \mathrm{~mL} / \mathrm{min}$ at $60^{\circ} \mathrm{C}$, and detected using an evaporative light scattering detector (ELSD, Alltech, Deerfield, IL, USA). The standards used were blue dextran $(2,000 \mathrm{kDa})$ and pullulans $(800,400$, 200, 100, and $20 \mathrm{kDa}$ ).

\section{Monosaccharide composition analysis}

The monosaccharide composition of the crude polysaccharide and fractionated polysaccharides was determined using a HPLC system, which consisted of a pump (Waters 2695, Waters Co., Milford, MA, USA), a column (SUGAR SH1011, $8.0 \mathrm{~mm} \times 300 \mathrm{~mm}$, Shodex, Showa Denko, Tokyo, Japan) and a refractive index detector (Waters 2414. Waters Co., Milford, MA, USA). After the hydrolysis of the 
polysaccharides $(60 \mathrm{mg})$ in $6 \mathrm{~N} \mathrm{HCl}$ at $100^{\circ} \mathrm{C}$ for $4 \mathrm{~h}, \mathrm{HCl}$ was removed by the evaporation with a dried stream of nitrogen. The hydrolysates $(10 \mu \mathrm{L})$ were injected into the

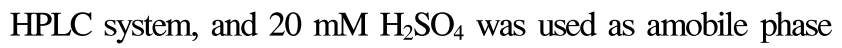
at a flow rate of $0.6 \mathrm{~mL} / \mathrm{min}$. The column temperature was maintained at $60^{\circ} \mathrm{C}$. The following monosaccharides were used as references: mannose, galactose, glucose, glucosamine and galactosamine (Sigma-Aldrich Co.).

\section{FT-IR spectroscopy analysis}

The crude polysaccharide and fractionated polysaccharides were pressed into $\mathrm{KBr}$ pellets. The FT-IR spectrum of polysaccharides was then obtained using a JASCO FT-IR spectrometer (300E; Jasco, Tokyo, Japan). The spectra were recorded at an absorbance mode from $4,000 \mathrm{~cm}^{-1}$ to $600 \mathrm{~cm}^{-1}$. The background was determined by using a blank KBr disk.

\section{Cell culture}

Murine macrophage cells (RAW 264.7 cells, Korean Cell Line Bank, Seoul, Korea) were cultured in Dulbecco's modified Eagle's medium (DMEM) supplemented with $10 \%$ fetal bovine serum (FBS, WELGENE Inc., Daegu, Korea) and antibiotics (100 U/mL penicillin and $100 \mu \mathrm{g} / \mathrm{mL}$ streptomycin; GIBCO, Rockville, MD, USA) at $37^{\circ} \mathrm{C}$ in a humidified atmosphere with $5 \% \mathrm{CO}_{2}$.

\section{Macrophage proliferation assay}

The MTT assay was used to evaluate the toxic effect of crude polysaccharide and fractionated polysaccharides on RAW 264.7. The RAW 264.7 cells in DMEM medium containing $10 \%$ FBS were plated in a 96-well microplate $\left(5 \times 10^{4}\right.$ cells/well in a volume of $\left.100 \mu \mathrm{L}\right)$ for $24 \mathrm{~h}$ and then cultured with different concentrations of crude polysaccharide $(0.5,1,2.5$, and $5 \mu \mathrm{g} / \mathrm{mL})$, fractionated polysaccharides $(0.05$, $0.1,0.25$, and $0.5 \mu \mathrm{g} / \mathrm{mL}$ ) or lipopolysaccharide (LPS, 0.1 $\mu \mathrm{g} / \mathrm{mL}$ ) for $24 \mathrm{~h}$. After incubation, MTT was added to each well to a final concentration of $0.5 \mathrm{mg} / \mathrm{mL}$. The plates were further incubated for $4 \mathrm{~h}$, and the produced formazan crystals were dissolved in dimethyl sulfoxide (Junsei Chemical Co., Osaka, Japan). The absorbance $(A)$ at $540 \mathrm{~nm}$ was measured using an enzyme linked immunosorbent assay (ELISA) reader (UVM-340, Biochrom Ltd., Cambridge, England). Proliferation was calculated as follows: activity $(\%)=$ $\left(\mathrm{A}_{\text {sample }} / \mathrm{A}_{\text {control }}\right) \times 100$, where $\mathrm{A}_{\text {sample }}$ and $\mathrm{A}_{\text {control }}$ are the absorbance of the sample and control, respectively.

\section{Nitric oxide production assay}

Nitric oxide (NO) secretion from macrophages and the nitrite concentration was determined using the Griess test RAW 264.7 cells were placed in a 96-well plate $\left(5 \times 10^{4}\right.$ cells/well in a volume of $100 \mu \mathrm{L}$ ) and incubated for $24 \mathrm{~h}$ at $37^{\circ} \mathrm{C}$. The cultured cells were treated with $100 \mu \mathrm{L}$ crude polysaccharide $(5 \mu \mathrm{g} / \mathrm{mL})$, fractionated polysaccharides $(0.05$, 0.1 and $0.25 \mu \mathrm{g} / \mathrm{mL}$ ) or LPS (final concentration $0.1 \mu \mathrm{g} / \mathrm{mL}$ ), which was used as a positive control. After incubation for $24 \mathrm{~h}$ at $37{ }^{\circ} \mathrm{C}, 100 \mu \mathrm{L}$ of the cultured cell supernatant was mixed with an equal volume of griess reagent $(1 \%$ sulfanilamide, and $0.1 \% \mathrm{~N}$-[1-naphthyl]ethylenediamine hydrochloride in distilled water) and left at room temperature for $10 \mathrm{~min}$. The absorbance at $540 \mathrm{~nm}$ was measured using a micro plate reader. The NO secretion from RAW264.7 cells was calculated by reference to a standard curve obtained with $\mathrm{NaNO}_{2}$.

\section{Cytokines production assay}

For cytokine determination, RAW 264.7 cells were cultured in the presence of crude polysaccharide $(5 \mu \mathrm{\mu g} / \mathrm{mL})$, fractionated polysaccharides $(0.05,0.1$, and $0.25 \mu \mathrm{g} / \mathrm{mL})$ or LPS (final concentration $0.1 \mu \mathrm{g} / \mathrm{mL}$ ). The cells were incubated for $24 \mathrm{~h}$, and the supernatant was collected and used to determine cytokine production following stimulation by crude and fraction polysaccharides. The production of TNF- $a$ and IL-6 was measured using commercial ELISA kits (Pepro tech Inc., Rocky Hill, NJ, USA).

\section{RT-PCR analysis of mRNA expression}

To evaluate the mRNA expression levels of inducible nitric oxide synthase (iNOS) and cyclooxygenase-2 (COX-2), total RNA from the crude polysaccharide and SF-1 $(0.05,0.1$, and $0.25 \mu \mathrm{g} / \mathrm{mL}$ ) or LPS (final concentration $0.1 \mu$ $\mathrm{g} / \mathrm{mL}$ )-treated RAW 264.7 cells were prepared using a total RNA $(1 \mu \mathrm{g})$ extraction kit (Qiagen., Hilden, Germany). The reverse transcription polymerase chain reaction (RT-PCR, Mastercycler ${ }^{\circledR}$ nexus, Eppendorf AG, Hamburg, Germany) was performed using the RevertAid First Strand cDNA Synthesis Kit (Thermo Fisher Scientific Inc., Waltham, MA, USA). Reverse transcriptase amplification was conducted with an initial denaturation $\left(94^{\circ} \mathrm{C}\right.$ for $\left.30 \mathrm{~s}\right)$, annealing $\left(55^{\circ} \mathrm{C}\right.$ for $30 \mathrm{~s}$ ), and extension $\left(72^{\circ} \mathrm{C}\right.$ for $\left.1 \mathrm{~min}\right)$, followed by a final extension step at $72{ }^{\circ} \mathrm{C}$ for $10 \mathrm{~min}$. The products obtained by RT-PCR were separated by electrophoresis (Mupid-ex, Advance, Tokyo, Japan) using a $1.2 \%$ agarose gel and stained with Eco view (Dae myung Science Co., Seoul, Korea). The 
gels were then viewed under UV transillumination. The sequences of primers used in this experiment were: $5^{\prime}$ CCCTTCCGAAGTTTCTGGCAGCAGC-3' (forward), and 5 'GGCTGTCAGAGCCTCGTGGCTTTGG-3' (reverse) for iNOS,; 5'CACTACATCCTGACCCACTT-3' (forward), and 5'ATGCTCCTGCTTGAGTATGT-3' (reverse) for COX-2,; 5'GTGGGCCGCCCTAGGCACCAG-3 (forward), and 5' GGAGGAAGAGGATGCGGCAGT-3' (reverse) for $\beta$-Actin.

\section{Statistical analysis}

All experiments were carried out in triplicate, and means \pm standard deviation (SD) or average values are reported. Duncan's multiple-range test was used to adjust for multiple comparisons, and null hypotheses were rejected at the 0.05 level. All data were analyzed using SPSS/Windows software (Version 19.0, SPSS Inc., Chicago, IL, USA).

\section{Results and discussion}

\section{Chemical composition analysis}

The immunomodulatory effects of marine polysaccharides have been found to be related to their structural features, such as chemical composition (uronic acid and sulfate content), average molecular weights $(M w)$, conformation, and functional groups $(22,23)$. The polysaccharides from $S$. plicata were fractionated using a preparative DEAE-SepharoseCL-6B column to obtain three main fractions, which were selected based on the total carbohydrate and uronic acid elution profile (designated as Styela plicata polysaccharides

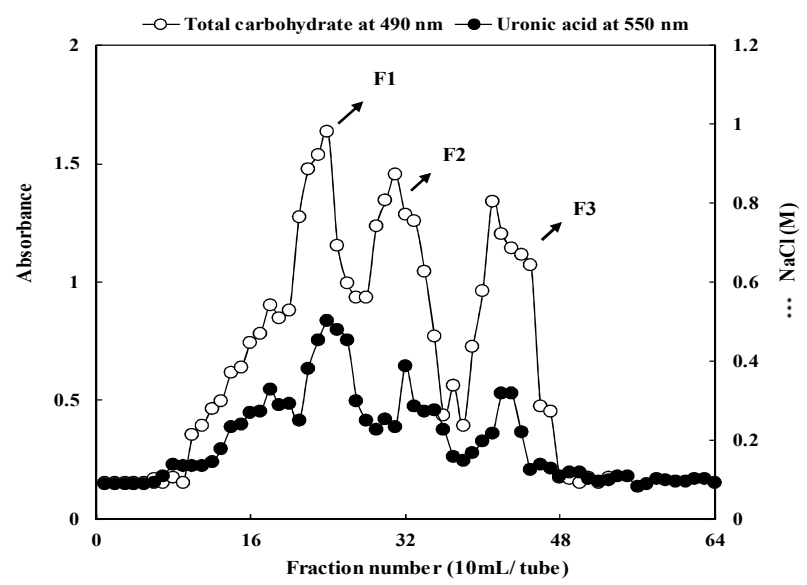

Fig. 1. Chromatogram of polysaccharides from Styela plicata on DEAE-Sepharose CL-6B.

The constituents were eluted with linear gradient between $0-1.0 \mathrm{M} \mathrm{NaCl}$ containing $0.5 \mathrm{M}$ sodium phosphate buffer $(\mathrm{pH} 6.0)$. Total carbohydrate and uronic acid were assayed by the phenol-sulfuric method, and carbazole reaction, respectively.
SF-1, SF-2, and SF-3) (Fig. 1). The yield, chemical properties, and monosaccharide compositions of the crude polysaccharide and fractionated polysaccharides from $S$. plicata was shown in Table 1 and Table 2. The yields of fractionated polysaccharides were SF-1 (7.02\%), SF-2 (24.18\%), and SF-3 (10.80\%). The constituents of the fractionated polysaccharides were mainly total carbohydrate (28.03-42.65\%) with various contents of uronic acid (17.01-23.76\%) and protein (1.48-9.23\%). The total carbohydrate slightly decreased from $42.65 \%$ (SF-1) to $28.03 \%$ (SF-3) when the $\mathrm{NaCl}$ concentration of the eluent at the ion-exchange chromatography increased to $1.0 \mathrm{M}$. The average molecular weights of SF-1, SF2 and SF-3 were estimated to be approximately $1,187,136$, and $28 \mathrm{kDa}$, respectively. The biological activity of polysaccharides depends on their structural features such as molecular weight, degree of sulfation, type of sugar, and glycosidic branching. Therefore, when polysaccharides of different molecular weights are studied, different biological activities can be expected. Moreover, the molecular interactions may be affected by the molecular weights of polysaccharides, there by resulting in different biological properties $(24,25)$.

The major monosaccharide compositions of the crude polysaccharide were galactose $(44.08 \%)$, glucose $(37.63 \%)$ and glucosamine $(10.74 \%)$, as well as a minor amount of mannose $(4.06 \%)$ and galactosamine $(3.49 \%)$. In general, the monosaccharide composition of ascidian polysaccharides differ significantly with species (26). Galactose (27.91$62.21 \%$ ), glucose (14.79-34.97\%), and glucosamine (13.35$28.31 \%$ ) are the three main sugars of the three fractionated polysaccharides, although they also contained considerable amounts of galactosamine (2.51-8.81\%). Furthermore, in the tunic of $S$. plicata, these polymers are the three main fractions, and they are markedly distinct in their molecular mass and chemical composition. The high-molecular-mass fraction contains a high proportion of galactose, whereas the other two fractions of low molecular mass contain a higher proportion of amino sugars, and glucose $(27,28)$. These results suggest that it is possible to obtain polysaccharides with various ionic strengths and chemical compositions by fractionating the crude polysaccharide using ion-exchange chromatography.

\section{FT-IR spectroscopy analysis}

FT-IR spectroscopy was used to investigate the structural features of the polysaccharides such as the monosaccharide type, glycosidic bonds, and functional groups (29). 
Table 1. The chemical properties of crude and fractionated polysaccharides isolated from Styela plicata

\begin{tabular}{ccccccc}
\hline Sample & $\begin{array}{c}\text { Yield } \\
(\text { dry basis, \%) }\end{array}$ & $\begin{array}{c}\text { Total carbohydrate } \\
(\text { glucose, \%) }\end{array}$ & $\begin{array}{c}\text { Uronic acid } \\
\left(\mathrm{GA}^{2}, \%\right)\end{array}$ & Sulfate $(\%)$ & $\begin{array}{c}\text { Protein } \\
\left.(\mathrm{BSA})^{3}, \%\right)\end{array}$ & $\begin{array}{c}\text { Molecular weight } \\
(\mathrm{kDa})\end{array}$ \\
\hline SP & $11.90 \pm 0.51^{\mathrm{b})}$ & $28.60 \pm 0.88^{\mathrm{c}}$ & $9.88 \pm 0.11^{\mathrm{d}}$ & $18.03 \pm 0.41^{\mathrm{d}}$ & $26.47 \pm 0.22^{\mathrm{a}}$ & - \\
SF-1 & $7.02 \pm 0.09^{\mathrm{c}}$ & $42.65 \pm 1.08^{\mathrm{a}}$ & $23.76 \pm 0.89^{\mathrm{a}}$ & $29.25 \pm 0.27^{\mathrm{a}}$ & $1.72 \pm 0.15^{\mathrm{c}}$ & 1,187 \\
SF-2 & $24.18 \pm 0.68^{\mathrm{a}}$ & $33.36 \pm 0.64^{\mathrm{b}}$ & $17.01 \pm 1.23^{\mathrm{c}}$ & $23.22 \pm 0.22^{\mathrm{c}}$ & $9.23 \pm 0.32^{\mathrm{b}}$ & 136 \\
SF-3 & $10.80 \pm 0.24^{\mathrm{b}}$ & $28.03 \pm 1.08^{\mathrm{c}}$ & $20.90 \pm 0.56^{\mathrm{b}}$ & $27.09 \pm 0.34^{\mathrm{b}}$ & $1.48 \pm 0.18^{\mathrm{c}}$ & 28 \\
\hline
\end{tabular}

${ }^{1)}$ SP, crude polysaccharide from Styela plicata; SF-1, polysaccharide fraction- I ; SF-2, polysaccharide fraction- II; SF-3, polysaccharide fraction-III.

${ }^{2}$ Uronic acid content was determined by the carbazole reaction, using galacturonic acid (GA) as a standard.

${ }^{3} \mathrm{BSA}$, bovine serum albumin.

${ }^{4}$ Means \pm SD ( $n=3$ ) within each column (a-d) followed by the same letter are not significantly different $(\mathrm{p}<0.05)$.

Table 2. The monosaccharide composition of fractionated polysaccharides isolated from Styela plicata

\begin{tabular}{cccccc}
\hline \multirow{2}{*}{ Sample $^{1)}$} & \multicolumn{5}{c}{ Monosaccharide composition (Area, \%) } \\
\cline { 2 - 6 } & Galactose & Glucose & Mannose & Glucosamine & Galactosamine \\
\hline SP & 44.08 & 37.63 & 4.06 & 10.74 & 3.49 \\
SF-1 & 71.40 & 14.79 & $\mathrm{nd}^{2}$ & 9.30 & 2.51 \\
SF-2 & 25.26 & 51.74 & nd & 19.48 & 3.52 \\
SF-3 & 27.91 & 25.30 & 9.67 & 28.31 & 8.81 \\
\hline
\end{tabular}

${ }^{1)}$ SP, crude polysaccharide from Styela plicata; SF-1, polysaccharide fraction- I ; SF-2, polysaccharide fraction- II; SF-3, polysaccharide fraction-III.

${ }^{2)}$ nd, not detectable below the limit at 0.001 .

The FT-IR spectra of SP, SF-1, SF-2 and SF-3 are shown in Fig. 2. Two characteristic absorptions of polysaccharides, a strong and wide absorption band of about $3,400 \mathrm{~cm}^{-1}$ for $\mathrm{O}-\mathrm{H}$ stretching vibrations and a strong absorption peak of about $2,900 \mathrm{~cm}^{-1}$ for $\mathrm{C}-\mathrm{H}$ stretching vibrations, were observed. Extensive absorption bands at $1,000^{-1}, 400 \mathrm{~cm}^{-1}$ corresponding to coupled $\mathrm{C}-\mathrm{H}$ and $\mathrm{S}-\mathrm{O}$ stretching and $\mathrm{C}-\mathrm{O}$ bending vibrations were observed in the FT-IR spectra of SP, SF-1,

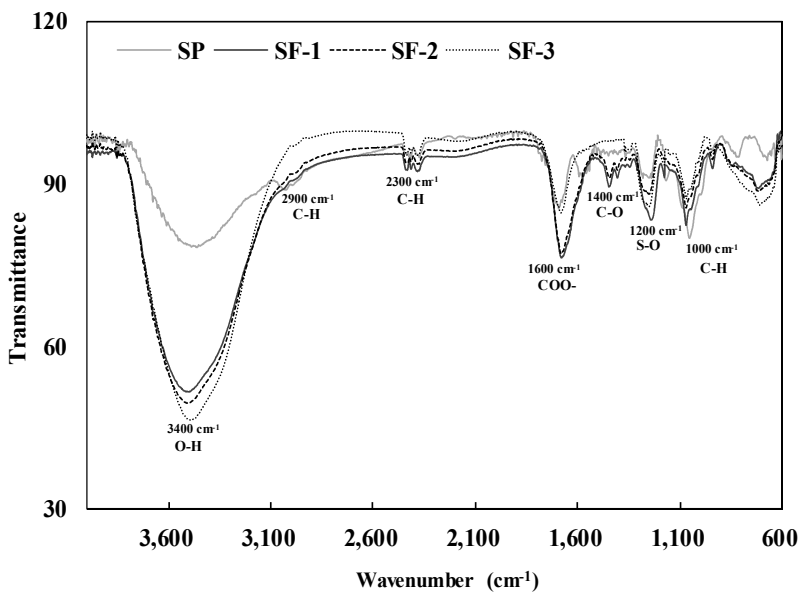

Fig. 2. FT-IR spectrum of the crude and fractionated polysaccharides from Styela plicata.

SP, crude polysaccharide from Styela plicata; SF-1, polysaccharide fraction- I; SF-2, polysaccharide fraction- II; SF-3, polysaccharide fraction-III. and SF-2, and these are the characteristic absorption bands of polysaccharides (11). Furthermore, the band at $1,600 \mathrm{~cm}^{-1}$ is characteristic of the deprotonated carboxylic acid group (COO-); this, considered with the analytical results (30), is evidence that S, SF-1, SF-2, and SF-3 contain uronic acid (12). In addition, the absorption peak at $1,200 \mathrm{~cm}^{-1}$ was assigned to the asymmetric stretching vibrations of SO, an indication of sulfate esters, confirming directly that S, SF-1, SF-2, and SF-3 were sulfated polysaccharides (31).

\section{Cell proliferation and nitric oxide production}

Macrophage cells are phylogenetically conserved and plays a key role in host defense and innate immune response. Macrophage activation is one self-defense mechanisms used to protect the host against pathogen infection (32). The crude polysaccharide and fractionated polysaccharides at concentrations between 0.5-5 $\mathrm{\mu g} / \mathrm{mL}$, and 0.05-0.25 $\mathrm{\mu g} / \mathrm{mL}$, respectively, has no toxicity on the RAW 264.7 (Fig. 3). Thus, test concentrations within these ranges were used to investigate the immunomodulatory effects.

Nitric oxide (NO) has been identified as a major effector molecule produced by macrophages and is involved in the regulation of apoptosis and in host defenses against microorganisms and tumor cells (33). The synthesis of NO by activated macrophages is an important cytotoxic/cytostatic 
(A)

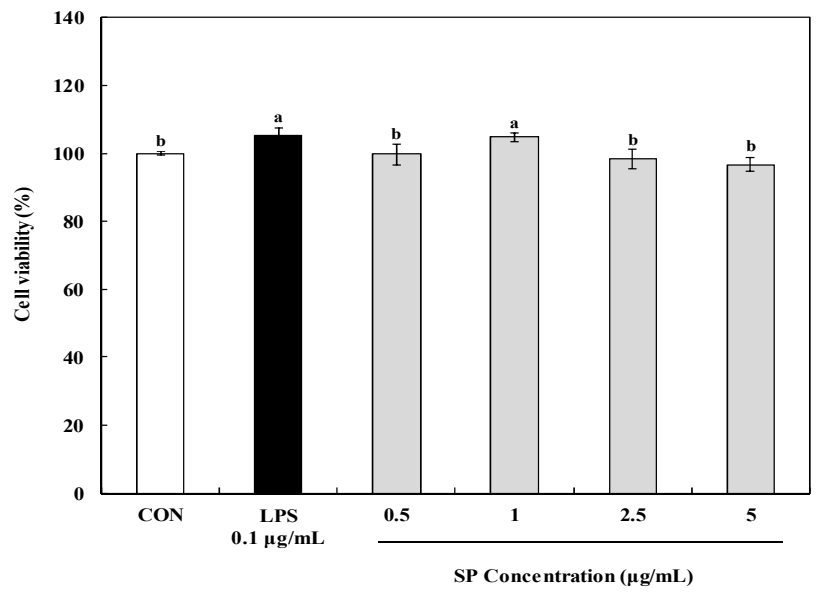

(B)

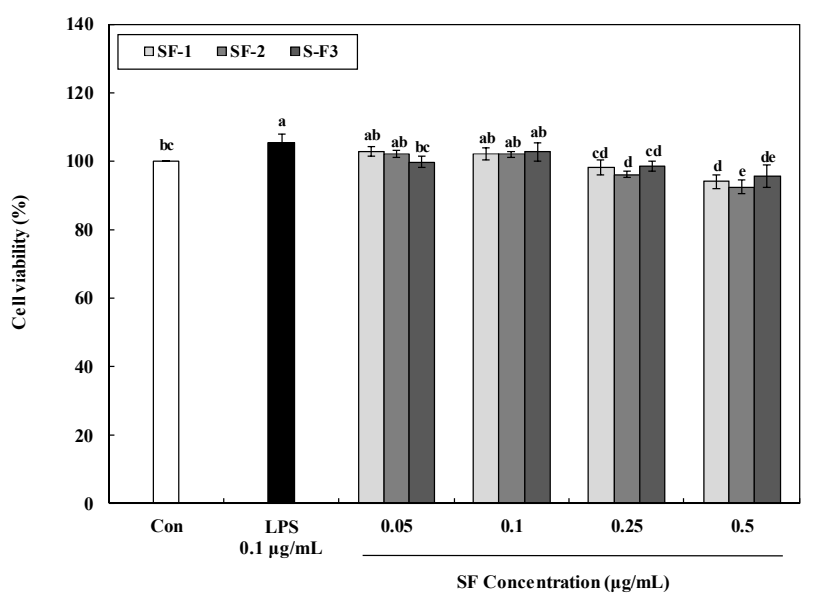

Fig. 3. Effect of crude polysaccharide (A), and fractionated polysaccharides (B) from Styela plicata on the cell viability of RAW 264.7 cell.

LPS, Lipopolysaccharide; SP, crude polysaccharide from Styela plicata; SF-1, polysaccharide fraction- I; SF-2, polysaccharide fraction- II; SF-3, polysaccharide fraction-III

mechanism of non-specific immunity (34). The NO production from RAW 264.7 cells treated with SF-1 was dose dependent, and $16.53 \mu \mathrm{M}$ NO was produced at the highest polysaccharide concentration $(0.25 \mu \mathrm{g} / \mathrm{mL})$. Significantly lower production of NO (maximum 7.89-11.43 $\mu \mathrm{M}$ ) was released from RAW 264.7 cells treated with the SF-2 and SF-3 $(0.25 \mu \mathrm{g} / \mathrm{mL})$ fractions. Minimal NO-releasing capacity, less than $5.17 \mu \mathrm{M}$, was observed for SP $(5 \mu \mathrm{g} / \mathrm{mL})$. Therefore, these results indicate that the SP fractions could have beneficial pharmacological effects via their ability to modulate macrophage function (Fig. 4), especially because these compounds have been shown to increase macrophage cytotoxicity against tumor cells, increase reactive oxygen species (ROS) and NO production, and enhance secretion of cytokines (35). According to a previous study, the level of NO release was proportionally related to the sulfate content of the polysaccharide (36). In addition, observed a relationship between the $\mathrm{Mw}$ and NO production from macrophages, reporting that higher $\mathrm{Mw}$ polysaccharides induced a greater production of NO from Raw 264.7 cells (37).

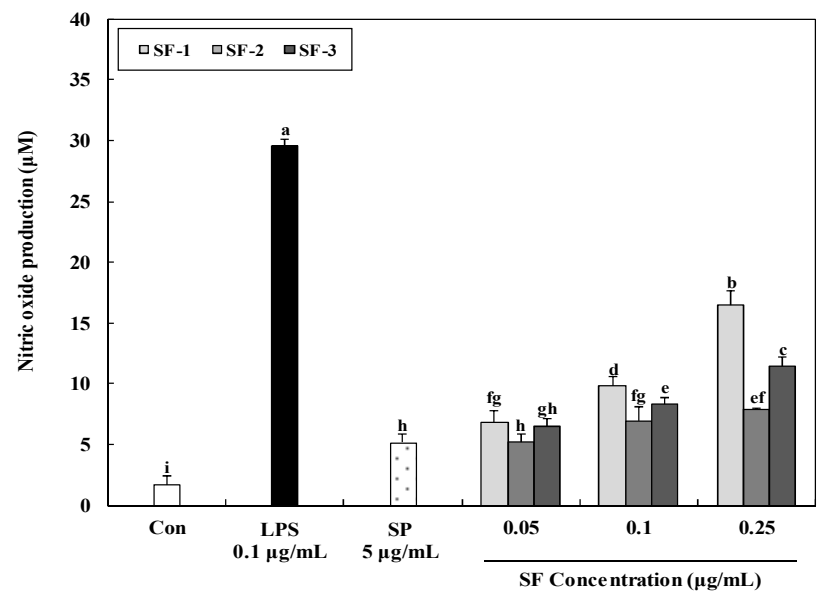

Fig. 4. Effects of fractionated polysaccharides from Styela plicata on the nitric oxide production by RAW 264.7 cell.

LPS, Lipopolysaccharide; SP, crude polysaccharide from Styela plicata; SF-1, polysaccharide fraction- I; SF-2, polysaccharide fraction- $\Pi$; SF-3, polysaccharide fraction-III.

\section{Cytokines production}

Cytokines are intercellular signaling proteins released by both immune and non-immune cells. Cytokines play important roles in controlling the homeostasis of the whole organism by the induction of cell differentiation, proliferation, and apoptosis, as well as defense functions such as immune responses and inflammatory reactions (38). To evaluate the effects of the crude polysaccharide and fractionated polysaccharides on cytokine secretion in RAW 264.7 macrophages, ELISA assays were performed to measure TNF- $a$ and IL-6 levels in the culture supernatants of RAW 264.7 cells treated with the polysaccharides. As shown in Fig. 5, SF-1 increased the secretion of TNF-a, and IL-6 in a dose-dependent manner, when the concentration of SF-1 was $0.25 \mu \mathrm{g} / \mathrm{mL}$, the production of TNF-a, and IL-6 was $89.96 \%$ and $42.45 \%$, respectively. These results show that SF-1 has significant immunomodulatory activity. In general, polysaccharide are highly diverse in their monosaccharide composition, glycosidic linkage patterns, molecular mass, conformation, degree of branching, and other physicochemical properties. These factors influence their immunomodulatory activity, as well as other bioactivity (13). The ability of SF-1 to stimulate RAW 264.7 macrophages to produce these cytokines strongly suggested that the SF-1 may have beneficial effects on early immunomodulation. 


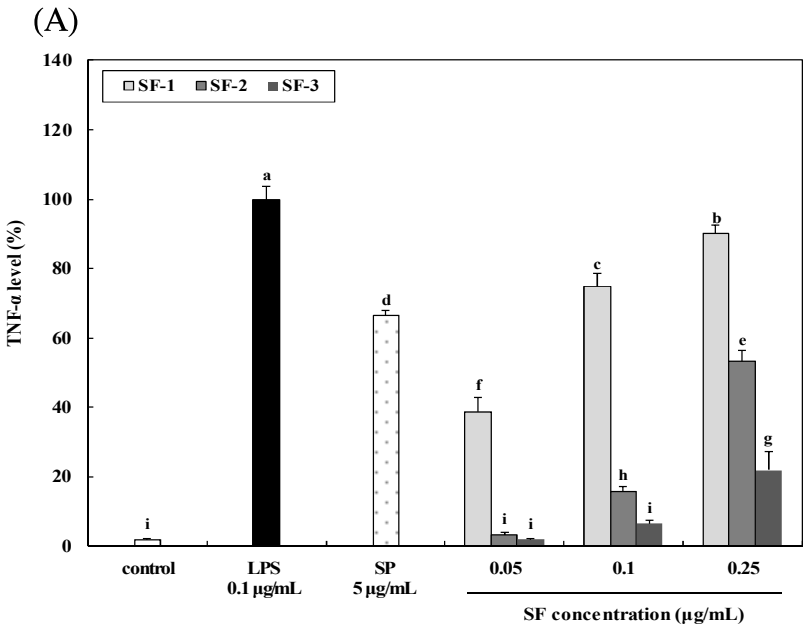

(B)

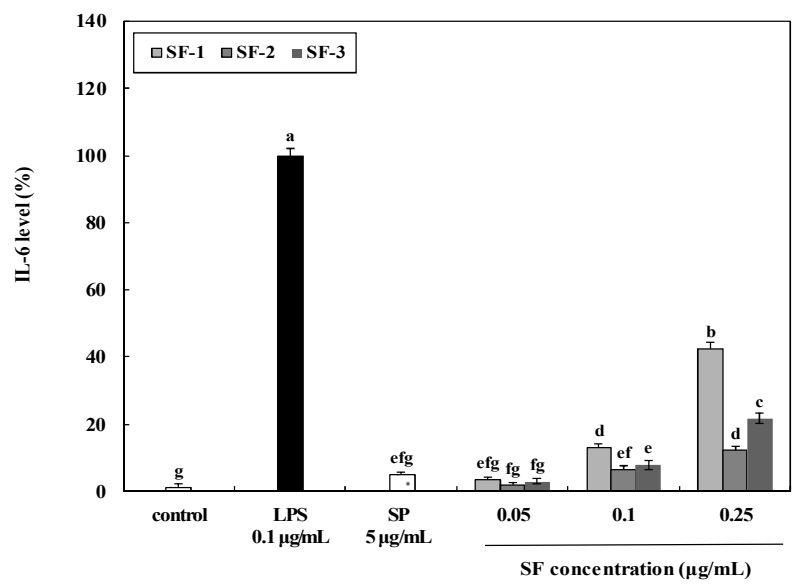

Fig. 5. Effects of fractionated polysaccharides from Styela plicata on the cytokine production by RAW 264.7 cell. (A) TNF-a, and (B) IL-6.

LPS, Lipopolysaccharide; SP, crude polysaccharide from Styela plicata; SF-1, polysaccharide fraction- I; SF-2, polysaccharide fraction- II; SF-3, polysaccharide fraction-III.

mRNA expression of iNOS and COX-2

The expression of iNOS, and COX-2 in macrophages is largely regulated by transcriptional activation, It has been suggested that activated macrophages also release some immune factors including iNOS, COX-2, and others (39). The mRNA expression of iNOS and COX-2 in RAW 264.7 cells by the crude and fractionated polysaccharides was determined by agarose gel analysis of the RT-PCR products using primers for iNOS and COX-2 mRNA (Fig. 6). The levels of mRNA expression of iNOS and COX-2 increased in a dose-dependent manner $(0.05-0.25 \mu \mathrm{g} / \mathrm{mL})$ after the application of SF-1, and this is similar to the levels generated by SP $(5 \mu \mathrm{g} / \mathrm{mL})$ and LPS $(0.1 \mu \mathrm{g} / \mathrm{mL})$ treatment. In addition, the expression of iNOS, and COX-2 was found to be statistically significant above $0.05 \mu \mathrm{g} / \mathrm{ml}$. Therefore, these results suggested that the increased NO production might be due to the enhanced mRNA expression of iNOS and COX-2 that was up-regulated in RAW 264.7 cells via activation by the polysaccharides (40). In conclusion, SF-1 has potent immunomodulatory activities, and our results suggest that these polysaccharides can be used as a functional food material.
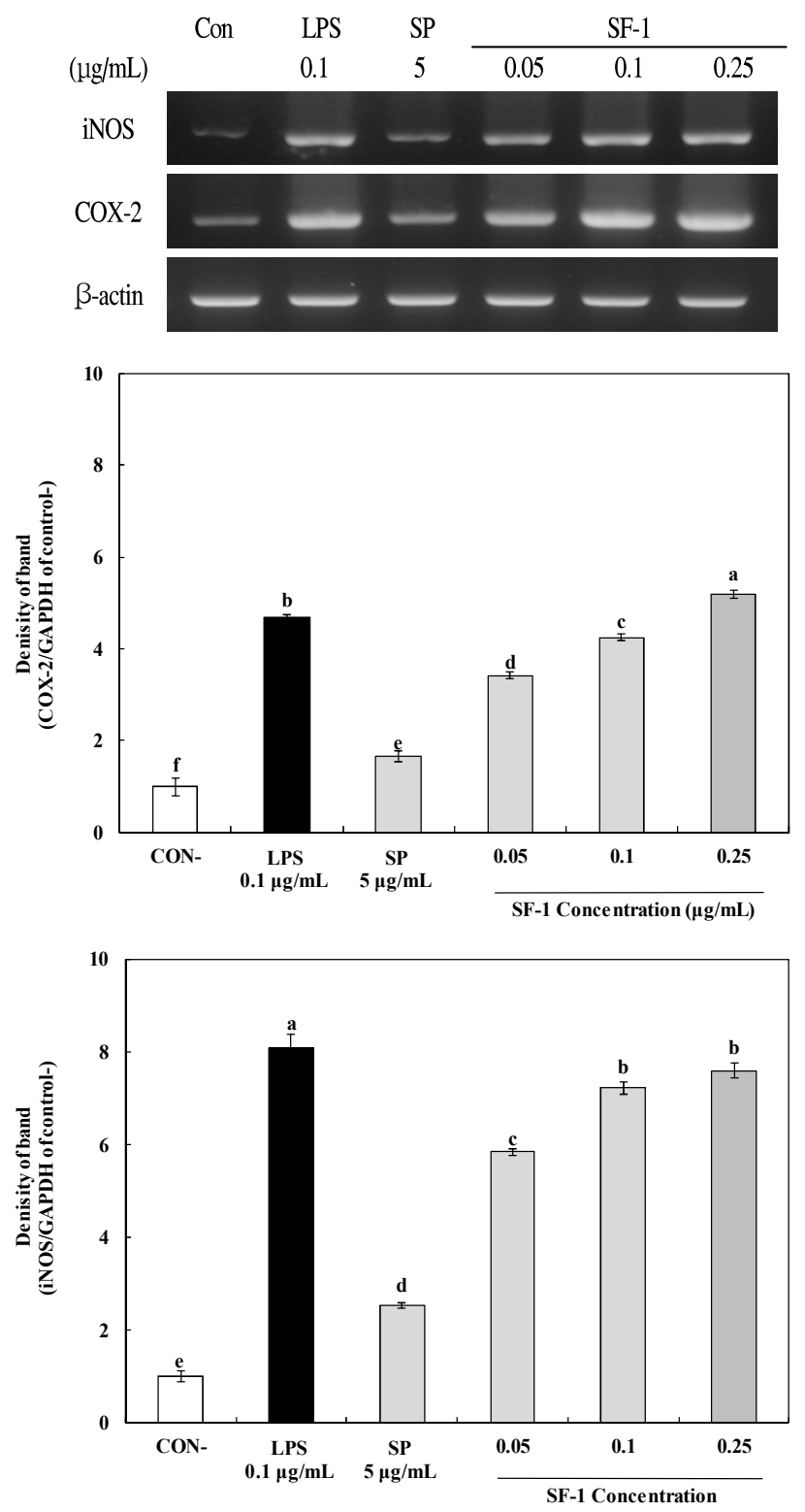

Fig. 6. RT-PCR analysis of iNOS and COX-2 mRNA expression by RAW 264.7 cell.

LPS, Lipopolysaccharide; SP, crude polysaccharide from Styela plicata, SF-1, polysaccharide fraction- I . 


\section{Acknowledgment}

This work was supported by research grants from Daegu Catholic University in 2017.

\section{References}

1. Hooper LV, Littman DR, Macpherson AJ (2012) Interactions between the microbiota and the immune system. Science, 336, 1268-1273

2. Klimp AH, De Vries EGE, Scherphof GL, Daemen T (2002) A potential role of macrophage activation in the treatment of cancer. Crit Rev Oncol Hematol, 44, 143-161

3. Commins SP, Borish L, Steinke JW (2010) Immunologic messenger molecules: cytokines, interferons, and chemokines. J Allergy Clin Immunol, 125, 53-72

4. Medzhitov R, Janeway C (2000) Innate immune recognition: mechanisms and pathways. Immunol Rev, 173, 89-97

5. Lee JS, Synytsya A, Kim HB, Choi DJ, Lee S, Lee J, Kim WJ, Jang S, Park YI (2013) Purification, characterization and immunomodulating activity of a pectic polysaccharide isolated from Korean mulberry fruit Oddi (Morus alba L.). Int Immunopharmacol, 17, 858-866

6. Li JE, Nie SP, Xie MY, and Li C (2014) Isolation and partial characterization of a neutral polysaccharide from Mosla chinensis Maxim. cv. Jiangxiangru and its antioxidant and immunomodulatory activities. J Funct Foods, 6, 410-418

7. Schepetkin IA, Quinn MT (2006) Botanical polysaccharides: macrophage immunomodulation and therapeutic potential. Int Immunopharmacol, 6, 317-333

8. Liu J, Willfor S, Xu C (2015) A review of bioactive plant polysaccharides: Biological activities, functionalization, and biomedical applications. Bioact Carbohydr Diet Fibre, 5, 31-61

9. Yang W, Wang Y, Li X, and Yu P (2015) Purification and structural characterization of Chinese yam polysaccharide and its activities. Carbohydr Polym, 117, 1021-1027

10. Ko SC, Kang MC, Lee JK, Byun HG, Kim SK, Lee SC, Jeon BT, Park PJ, Jung WK, Jeon YJ (2011) Effect of angiotensin I-converting enzyme (ACE) inhibitory peptide purified from enzymatic hydrolysates of Styela plicata. Eur Food Res Technol, 233, 915-922
11. Yang Y, Liu D, Wu J, Chen Y, Wang S (2011) In vitro antioxidant activities of sulfated polysaccharide fractions extracted from Corallina officinalis. Int J Biol Macromol, 49, 1031-1037

12. Gan D, Ma L, Jiang C, Xu R, Zeng X (2011) Production, preliminary characterization and antitumor activity in vitro of polysaccharides from the mycelium of Pholiota dinghuensis Bi. Carbohydr Polym, 84, 997-1003

13. Sun Z, Peng Y, Zhao WW, Xiao LL, Yang PM (2015) Purification, characterization and immunomodulatory activity of a polysaccharide from Celosia cristata. Carbohydr Polym, 133, 337-344

14. David GK, Marshall DJ, Riginos C (2010) Latitudinal variability in spatial genetic structure in the invasive ascidian, Styela plicata. Mar Biol, 157, 1955-1965

15. Maltagliati F, Lupi L, Castelli A, Pannacciulli FG (2016) The genetic structure of the exotic ascidian Styela plicata (Tunicata) from Italian ports, with a re-appraisal of its worldwide genetic pattern. Mar Ecol, 37, 492-502

16. Seo BY, Kim JM, Lee SC, Park EJ (2009) Antigenotoxic and anticarcinogenic effects of Styela plicata. J Korean Soc Food Sci Nutr, 38, 839-845

17. Nair SV, Burandt M, Hutchinson A, Raison RL, Raftos DA (2001) A C-type lectin from the tunicate, Styela plicata, that modulates cellular activity. Comp Biochem Part C: Toxicol Pharmacol, 129, 11-24

18. Dubois M, Gilles KA, Hamilton JK, Rebers PA, Smith F (1956) Colorimetric method for determination of sugars and related substances. Anal Chem, 28, 350-356

19. Cesaretti M, Luppi E, Maccari F, Volpi N (2003) A 96-well assay for uronic acid carbazole reaction. Carbohydr Polym, 54, 59-61

20. Dodgson KS, Price RG (1962) A note on the determination of the ester sulphate content of sulphated polysaccharides. Biochem J, 84, 106-110

21. Lowry OH, Rosebrough NJ, Farr AL, Randall RJ (1951) Protein measurement with the Folin phenol reagent. J Biol Chem, 193, 265-275

22. Schepetkin IA, Quinn MT (2006) Botanical polysaccharides: macrophage immunomodulation and therapeutic potential. Int Immunopharmacol, 6, 317-333

23. Leiro JM, Castro R, Arranz JA, Lamas J (2007) Immunomodulating activities of acidic sulphated polysaccharides obtained from the seaweed Ulva rigida C. Agardh. Int Immunopharmacol, 7, 879-888

24. Zhang Q, Yu P, Li Z, Zhang H, Xu Z, Li P (2003) Antioxidant activities of sulfated polysaccharide fractions 
from Porphyra haitanesis. J Appl phycol, 15, 305-310

25. Zhou G, Sun Y, Xin H, Zhang Y, Li Z, Xu Z (2004) In vivo antitumor and immunomodulation activities of different molecular weight lambda-carrageenans from Chondrus ocellatus. Pharmacol Res, 50, 47-53

26. Pavao MS, Albano RM, Lawson AM, Mourao PA (1989) Structural heterogeneity among unique sulfated L-galactans from different species of ascidians (tunicates). J Biol Chem, 264, 9972-9979

27. Mourao PA, Perlin AS (1987) Structural features of sulfated glycans from the tunic of Styela plicata (Chordata Tunicata). Eur J Biochem, 166, 431-436

28. Albano RM, Mourão PA (1986) Isolation, fractionation, and preliminary characterization of a novel class of sulfated glycans from the tunic of Styela plicata (Chordata Tunicata). J Biol Chem, 261, 758-765

29. Yang L, Zhang LM (2009) Chemical structural and chain conformational characterization of some bioactive polysaccharides isolated from natural sources. Carbohydr Polym, 76, 349-361

30. Jiang C, Wang M, Liu J, Gan D, Zeng X (2011) Extraction, preliminary characterization, antioxidant and anticancer activities in vitro of polysaccharides from Cyclina sinensis. Carbohydr Polym, 84, 851-857

31. Qiao D, Hu B, Gan D, Sun Y, Ye H, and Zeng X (2009) Extraction optimized by using response surface methodology, purification and preliminary characterization of polysaccharides from Hyriopsis cumingii. Carbohydr Polym, 76, 422-429

32. Wang ML, Hou YY, Chiu YS, Chen YH (2013) Immunomodulatory activities of Gelidium amansii gel extracts on murine RAW 264.7 macrophages. J Food Drug Anal, 21, 397-403

33. Yu Q, Nie SP, Li WJ, Zheng WY, Yin PF, Gong DM, Xie MY (2013) Macrophage immunomodulatory activity of a purified polysaccharide isolated from Ganoderma atrum. Phytother Res, 27, 186-191
34. Kadowaki T, Ohno S, Taniguchi Y, Inagawa H, Kohchi C, Soma GI (2013) Induction of nitric oxide production in RAW264. 7 cells under serum-free conditions by O-antigen polysaccharide of lipopolysaccharide. Anticancer Res, 33, 2875-2879

35. Ruotsalainen M, Hirvonen MR, Hyvarinen A, Meklin T, Savolainen K, Nevalainen A (1998). Cytotoxicity, production of reactive oxygen species and cytokines induced by different strains of Stachybotrys sp. from moldy buildings in RAW264.7 macrophages. Environ Toxicol Pharmacol, 6, 193-199

36. Leiro JM, Castro R, Arranz JA, Lamas J (2007). Immunomodulating activities of acidic sulphated polysaccharides obtained from the seaweed Ulva rigida C. Agardh. Int Immunopharmacol, 7, 879-888

37. Schepetkin IA, Xie G, Kirpotina LN, Klein RA, Jutila MA, Quinn MT (2008) Macrophage immunomodulatory activity of polysaccharides isolated from Opuntia polyacantha. Int Immunopharmacol, 8, 1455-1466

38. Wang W, Zou Y, Li Q, Mao R, Shao X, Jin D, Zheng D, Zhao T, Zhu H, Zhang L, Yang L, Wu X (2016) Immunomodulatory effects of a polysaccharide purified from Lepidium meyenii Walp. on macrophages. Process Biochem, 51, 542-553

39. Na YS, Kim WJ, Kim SM, Park JK, Lee SM, Kim SO, Synytsya A, Park YI (2010) Purification, characterization and immunostimulating activity of water-soluble polysaccharide isolated from Capsosiphon fulvescens. Int Immunopharmacol, 10, 364-370

40. Karnjanapratum S, Tabarsa M, Cho M, You S (2012) Characterization and immunomodulatory activities of sulfated polysaccharides from Capsosiphon fulvescens. Int J Biol Macromol, 51, 720-729 